\title{
Т.В. Метляева
}

Владивостокский государственный университет экономики и сервиса

ВлаАивосток. Россия

\section{Особенности формирования речевого имиджа мичности}

Рассматриваются подходы к формированию речевого имиАжа мичности в контексте его индивиАуальных особенностей. Анализируются приемы построения имиджа как результата определенной целенаправленной активности со стороны субъекта. Аемонстрируется необходимость эмоциональных взаимоотношений со стороны имидженосителя к партнеру или Аругим ^юАям, проявления ценностно-мотивационного начала. Подчеркивается важность владения культурой речи как составляющей общей культуры человека, риторическими приемами, языковой выразительностью. Рассмотрены три составные части речевого мастерства: техника речи, могика звучащей речи, словесное действие.

Представлены результаты исслеАования, посвященного изучению особенностей построения речевого имилжа. Обоснованы необходимость активной позиции человека, формирующего свой речевой имиАж, его мотивационная и целевая направленность, опора на внутренние личностные качества: самоощущение, поведенческие, эмоциональные, познавательные характеристики субъекта. Отмечено, что в качестве показателей речевого имиАжа выступают владение правияами устной речи, законами ^огики, умение говорить четко, грамотно и выразительно.

Ключевые слова и словосочетания: речевой имиАж, индивидуальность, активность, языковая выразительность, словесное Аействие, паравербальный язык.

\section{T.V. Metliaeva}

Vladivostok State University of Economics and Service

Vladivostok. Russia

\section{Peculiar characteristics of speech image formation}

The article examines approaches to the speech image formation of an individual in the context of one's peculiar characteristics. Image creation methods as a result of person's activity are analyzed. The importance of individual's emotional attitude is highlighted. Special attention is given to the importance of speech culture as a part of person's culture. The authors also underline the significance of rhetorical techniques as well as expressiveness in language. They describe the following three elements of speech skills: articulation, spoken language logic and verbal expression. The paper presents empirical findings of the study focused on the peculiarities of speech image formation, the design which is carried out with students of department and VVSU technology and the students attending master classes of this department. Aspects concerning image formation are considered. Attention is given to motivation and aims (pragmatic and/or psychological orientation) and to an internal (self-concept and self-awareness) type and an external (perception of the wider public) type of an image.

Speech image criteria include: knowledge of the oral speech and reasoning rules together with an ability to speak distinctly, eloquently and correctly. The authors use structural-functional method that helps to examine the formation of a person's image and the role of speech as a characteristic of an image in full detail. The structural elements of speech image are analyzed as well. The authors pay great attention both to oral speech reasoning and elocution (mastering of articulation and breathing exercises skills) in the process of speech image formation. The theoretical aspects of image formation based on the scientific studies of Shepel,

Татьяна Викторовна Метляева - канд. культурологии, доцент кафедры дизайна и технологий; 690014, Россия, Владивосток, ул. Гоголя, 41; e-mail: Metlaevatv@mail.ru.

Tatyana Viktorovna Metliaeva - candidate of cultural science, associate professor of Chair of Design and Technologies. 
Perelygina, Yakovleva are analyzed. The techniques of speech image formation studied by Issers, Karaulova and Fomina are also considered.

Keywords: speech image, identity, activity, language expressiveness, verbal action, paraverbal language.

\section{Введение}

В современной культуре довольно часто используют понятие «имидж» не только применительно к товару, организации, услуге, но и к личности. Это понятие прочно вошло в повседневный обиход и широко применяется как в целях рекламы и пропаганды позиционируемого объекта, так и для достижения успеха человеком в личностном и профессиональном плане. Актуальность темы исследования речевого имиджа личности продиктована сложившейся социокультурной ситуацией, условиями тотальной компьютеризации, когда человеческое общение заменяют «гаджеты», а «живое слово» - сокращенные фразы СМС-сообщений.

Современный образованный человек, а особенно специалист, чья деятельность касается сферы «человек-человек», должен уметь построить любое монологическое высказывание в устной и письменной форме в зависимости от адресата, цели, темы и ситуации общения. Необходимо уметь строить диалог, знать технику постановки вопросов и технику ответов на них, чтобы получить вразумительный ответ от собеседника (например, во время беседы или переговоров), направить процесс передачи информации в нужное русло, перехватить и удержать инициативу в диалоге, активизировать внимание собеседника, сделать общение наиболее эффективным. Выпускник высшего учебного заведения должен владеть определенными формулами речи, чтобы корректно выражать свои чувства и эмоции, нормами речевого и невербального этикета, уметь использовать весь богатый потенциал средств речевого воздействия, стилистические приемы (тропы, фигуры), имеющиеся в русском языке.

Чаще всего исследователи в области имиджа сводят понятие речевого имиджа к владению культурой речи и построению правильного слововыражения, рассматривая данное направление либо в связи с формированием образа политика, телеведущего, либо в применении к другой личности публичной сферы деятельности. Данное направление имиджа исследуется в работах таких авторов, как В.М. Шепель, А.А. Калюжный, Н.А. Фомина, А.В. Быков и др. Однако назрела необходимость исследования данного аспекта индивидуального имиджа применительно к любой личности, независимо от ее сферы, целей и способов деятельности.

Предмет исследования, источниковая база исследования, противоречия в имеющихся исследованиях и авторская позиция

В данной статье наш исследовательский интерес связан с рассмотрением некоторых особенностей построения речевого имиджа личности. В исследовании имиджа и особенностей его построения значим подход к его пониманию через субъект-субъектное взаимодействие (Е.Б. Перелыгина) [6].

Анализируются теоретические аспекты формирования имиджа, рассматриваемые в отечественной науке такими авторами как В.М. Шепель, Е.Б. Перелыгина, Е.Л. Яковлева, приемы формирования речевого имиджа косвенно анализируются в работах О.С. Иссерс, Ю.Н. Караулова, Н.А Фоминой. 
Предметом данного исследования являются особенности формирования речевого имиджа личности.

Цель: исследовать особенности формирования речевого имиджа личности в процессе построения его индивидуального образа.

Задачи:

- проанализировать подходы к определению понятий «индивидуальный имидж личности», «речевой имидж»;

- выявить приемы построения индивидуального речевого имиджа.

В работе применялись личностно-деятельностный подход и структурно-функциональный метод, позволяющий подробно рассмотреть структуру индивидуального имиджа и основное предназначение речи в этой структуре. В связи с чем большое внимание автор уделяет не только логике звучащей речи, активному словесному действию в процессе формирования речевого имиджа личности, но и технике речи (тренировка дикции, владение навыками артикуляционной, дыхательной гимнастики).

\section{Основная часть}

В современной науке индивидуальный имидж личности, представляя собой сложное и многогранное социально-психологическое явление, понимается как символический образ субъекта, создаваемый в процессе субъект-субъектного взаимодействия [6], как эффект личного обаяния [9], как мнение об объекте, возникшее в психике группы людей на основе образа, сформированного в результате либо прямого восприятия ими тех или иных характеристик данного объекта, либо косвенного - на основе восприятия уже оцененного кем-то образа [5].

Таким образом, имидж является психологическим образованием, напрямую связанным с индивидуально-личностными особенностями человека, которые проявляются в деятельности по созданию личностного имиджа. При этом индивидуальный имидж человека трактуется не только как его внешность (лицо, прическа, стиль одежды и т.д.), но и как все характеристики, доступные восприятию и создающие в совокупности представление о нем как о личности, об индивидуальности: то, как он выглядит, одевается, чем увлекается, как действует, что читает, что и как говорит и проч.

Весьма важно изучать те характеристики личности и индивидуальности, которые оказываются значимыми для возникновения или формирования и функционирования имиджа человека как объективного, так и субъективного социально-психологического явления.

В процессе формирования имиджа личности проявляются три наиболее обобщенные, интегральные переменные, характеризующие сущность целостной личности и ее индивидуальности: активность, направленность и саморегуляция, характеризующиеся, с одной стороны, непроизвольными психофизиологическими особенностями, тесно связанными с темпераментом человека, а с другой - произвольными, социально-психологическими, социально-культурными характеристиками личности, формируемыми в большей мере средовыми факторами и социальными отношениями. 
Имидж возникает как результат целенаправленной активности со стороны субъекта. При этом, как и любая другая, деятельность по созданию имиджа начинается с мотива, в основе которого лежит либо прагматическая цель, связанная с желанием использовать имидж для более эффективного социального влияния и достижения при его помощи определенного успеха, либо психологическая, связанная с потребностью человека в улучшении его внутренних, личностных качеств, приближении к его идеальному образу, повышении своей самооценки и т.д.

Выделяют различные виды имиджа: внутренний - аналог самоощущения, названный В.М. Шепелем «Я-концепция» субъекта [9], и внешний, создаваемый для восприятия окружающих в процессе субъект-субъектного взаимодействия [6]; реактивный, который формируется в результате стремления соответствовать ожиданиям окружающих как реакция на эти ожидания; активный, при формировании которого учитываются не только ожидания окружающих, но и собственные ожидания человека по отношению к самому себе, позволяющий человеку реализовать себя, свои чувства, эмоции [10].

Для создания имиджа человек прилагает определенные волевые усилия, поэтому важную роль в этом процессе играет механизм волевой регуляции, т.е. побуждение к действию.

Кроме того, при создании имиджа проявляется глубинная сущность человека, определяющая его уникальное, своеобразное, неповторимое отношение к окружающему миру и к самому себе через его эмоции, обладающие мотивирующей силой и помогающие более осознанно и целенаправленно строить свой имидж [10]. При этом эмоциональный интеллект [7], то есть понимание своих и чужих эмоций, очень важен для создания имиджа человека.

Таким образом, при изучении индивидуального имиджа необходим личностнодеятельностный подход. Причем деятельность личности по созданию имиджа следует рассматривать в единстве психодинамической, мотивационной, эмоциональной, культурной и других сфер личности человека.

Все эти аспекты особенно значимы при рассмотрении вербальной составляющей имиджа или вербального имиджа, так как именно речь является одной из основных и объективных характеристик человека, способных ярко и отчетливо высветить как его внутреннее богатство, так и представить все его негативные моменты. Кроме того, именно техника «очаровывания словом», в первую очередь, формирует технологию самопрезентации [9].

Чаще всего к вербальному имиджу относят то, что и как говорит или пишет человек, и основное внимание сосредоточивают на культуре его речи, анализе наиболее распространенных ошибок. На наш взгляд, речевые аспекты имиджа личности должны касаться как культуры речи (составляющей общей культуры человека), так и риторического или ораторского мастерства, а также языковой выразительности и техники речи. Ведь речевая деятельность, как и всякая другая, определяется единством двух сторон: внешней, исполнительской, реализующей саму деятельность, и внутренней, внешне не наблюдаемой, но осуществляющей ее организацию, планирование, программирование и обусловленной сложным единством и взаимодействием потребностей, эмоций, восприятия, внимания, мышления, памяти, опережающего 
отражения и т.п., которые выступают в качестве общефункциональных психологических механизмов и культурных особенностей этой деятельности.

Речь несет на себе отпечаток различных индивидуальных особенностей человека, «языковой личности». Под языковой личностью понимается личность, выраженная в языке (текстах) и через язык [3], совокупность способностей и характеристик человека, обусловливающих создание и восприятие им речевых произведений [7]. Также при формировании речевого имиджа немаловажным показателем является способность человека к использованию различных тактик в вербальном взаимодействии, что демонстрирует его склонность к искусству перевоплощения и умение понимать другого человека [1].

Важными аспектами в формировании речевого имиджа личности, наряду с вышеперечисленными, являются такие аспекты, как чистота, уместность, выразительность речи, демонстрация яркого личностного начала человека, «диалогичность» в процессе коммуникации, грамотность речи. Однако немаловажную роль играют и паравербальные характеристики общения (тон, тембр, скорость, паузы). Судя по речи человека, можно раскрыть и обнаружить богатство или ущербность внутреннего мира, общий уровень культуры и образования, так как всякое речевое произведение представляет основную «суть» его автора.

Именно поэтому понятие «речевое мастерство» интегрирует в себе разного рода подходы к освоению «звучащего слова». Это и сценическая речь, и культура речи, и ораторское искусство, и искусство «живого слова». В сущности, все эти понятия содержат один корень, рассматриваются на одной основе и имеют одну и ту же цель - овладение живой, образной, выразительной, доходчивой речью.

Три части составляют основу речевого мастерства при формировании индивидуального имиджа личности:

1) техника речи (тренировка дикции, дыхания, голоса; овладение орфоэпическими правилами);

2) логика звучащей речи, то есть умение логически верно вскрыть и донести до слушателя мысль, заключенную в тексте;

3) словесное действие - умение импровизировать в логически выстроенном тексте, выполнять идейно-творческие задачи.

Огромную роль при формировании имиджевого «портрета» личности играет мастерство публичного выступления. Ораторское искусство предполагает владение даром красноречия и риторикой. «Риторика учит говорить красиво... Красноречие украшает личность выступающего, эффективно служит имиджу. Любое удавшееся речевое событие приносит удовлетворение, желание следующего выступления. Главное - в речевом общении следует знать, что сказать, где сказать и как сказать» [5].

Тщательная подготовка - важная составляющая ораторского искусства, которая требует значительных усилий по овладению методикой устного выступления.

Обозначим важные элементы:

- знание предмета выступления;

- владение методикой устной речи; 
- тщательная подготовка к каждому выступлению, которая обеспечит стабильность в их успешности;

- активная практика в публичной речи позволяет достичь вершины ораторского искусства.

Выступление на аудитории строится по следующим этапам мотивационной последовательности.

Первый этап - фокусировка и удержание внимания. В начале своего выступления оратору необходимо сконцентрировать внимание аудитории, наладить контакт, относительную непринужденность в общении. Для того, чтобы оратор чувствовал себя уверенно перед слушателями, ему необходимо заранее спланировать свою речь. В процессе подготовки к выступлению он должен укреплять веру в способность управлять аудиторией, тренироваться в овладении конкретными риторическими приемами.

Второй этап - формирование и поддержание интереса. Чтобы удерживать внимание аудитории, необходимо выдавать информацию порционно. Убеждающая аргументация, материал, составленный в форме поиска истины, а также интонационная окраска, увеличение или уменьшение скорости речи, - приемы, позволяющие поддерживать интерес аудитории на протяжении всего выступления оратора.

Третий этап - конкретизация и визуализация предмета. Абстрактные рассуждения должны чередоваться с конкретными фактами, иллюстрирующими эти рассуждения. Опытные ораторы используют тонкие риторические приемы, цитаты, примеры.

Четвертый этап - общий вывод из разных фрагментов речи, обычно он занимает не более 5\% времени всей речи, однако роль его несравненно выше. В конце необходимо резюмировать речь, повторить основные выводы и положения, призвать к действию. Начало и конец выступления должны быть связаны друг с другом [2].

Помимо начитанности и большого «багажа» знаний по теме выступления. имидженоситель должен обладать следующими необходимыми качествами для формирования ораторского мастерства:

- видеть будущее и уметь его предвосхищать;

- брать на себя ответственность;

- обладать развитыми коммуникативными навыками (слышу, говорю, анализирую);

- иметь четкие цели;

- уметь ставить цели, идти к ним и анализировать процесс их достижения;

- хорошо знать себя, уметь анализировать свои возможности и способности. Самопознание должно занимать не меньше времени, чем подготовка к новому выступлению. Сюда же можно отнести и самодисциплину. Успешный оратор - это всегда очень дисциплинированный человек, достаточно требовательный и к себе, и к окружающим;

- у уметь мгновенно применять только что полученные знания и быть достаточно гибким, чтобы меняться вместе с системой. Многие люди по своей природе таковы, что склонны не реализовывать, а накапливать свой потенциал. Им всегда чего-то не хватает. Для того, чтобы получить новую работу, нужно еще чему-нибудь поучиться, чтобы сделать ответственный шаг, необходимо еще немного подумать. 
Между тем они уже давно могли бы не накапливать потенциал, а развивать и применять на практике свои сильные качества.

Значительно снижает впечатление от публичного выступления (которым является любое выступление перед аудиторией более трех человек) - «штампованность», «обезличенность», чрезмерная книжность, речевые ошибки, использование диалектизмов. Во многих литературных источниках по речевому искусству представлено доказательство, что каждый человек способен понимать за минуту 650-700 слов, а говорить в среднем 150-160 слов, поэтому у слушателя всегда достаточно времени на оценку говорящего: его жестов, мимики, позы, интонации, оттенков психологического состояния.

Владение правилами устной речи, законами логики, умение говорить четко, грамотно и выразительно нужны сегодня каждому человеку, стремящемуся добиться каких-либо успехов.

В основе ораторского искусства лежат принципы риторики: подбор аргументов, их распределение в ходе логических доказательств, стиль и структура построения речи. Искусство красноречия основано в первую очередь на объективной, систематизированной информации, одним из критериев красноречия является именно информационный аспект речи. Однако только информативность публичного выступления не дает желаемого эффекта, необходима еще и ее эмоциональная содержательность, что сближает позиции оратора и актера.

Немаловажную роль в процессе создания речевого имиджа играет поведение оратора, составные элементы которого: жесты, мимика, эмоции, манера изложения, варьирование интонации, соблюдение регламента.

Формирование коммуникативных навыков является не только приоритетным направлением для любого специалиста сферы «человек-человек», но и важнейшими компонентом речевого имиджа.

Это такие навыки, как:

1) умение понимать уместность/неуместность или возможность/невозможность речевого акта в определенной ситуации общения;

2) осознание коммуникативной цели и её выражение (прямое или косвенное, эксплицитное (разъясняющее) или имплицитное (связывающее);

3) ориентация на адресата (выбор темы, использование средств привлечения внимания, поддерживания речевого контакта, отбор языковых, в том числе эмоционально-экспрессивных, функционально-стилистических, средств с учетом симметричности/ несимметричности социальных ролей коммуникантов, близости/ неблизости, официальности/неофициальности отношений и т. д.);

4) выбор речевой стратегии и тактик в соответствии с коммуникативной целью, шкала их варьирования;

5) жанровое оформление речи;

6) соотношение фактического и информативного, субъектно-модального и предметно-содержательного планов;

7) тональность общения;

8) характер использования коммуникативных импликатур (оправданность/ неоправданность) и их расшифровка; 
9) соотношение вербальных и невербальных средств общения;

10) этикетные нормы [4].

Важным фактором эффективности речевого взаимодействия в построении индивидуального имиджа является осознание индивидом целевой установки речи (зачем он начинает говорить, писать, вступает в общение). Это может быть организация совместной деятельности через общение, влияние на других посредством речи, активизация усилий по решению его собственных проблем и т.д. Показательны при этом способности воспринять и оценить речевое поведение собеседника, наладить обратную связь, организовав диалогическое общение; умение управлять общением, расположить аудиторию, собеседника к взаимодействию.

Ориентированность современного общества на формирование образа успешной личности диктует также необходимость умелого владения речевым этикетом, знания и использования этических норм общения [8]. В реализации этого большую роль играют тактичность, толерантность, общительность, стремление понять другого, чувство меры, творческая активность и др. Эти качества являются производными от уровня развития целого ряда способностей: прогностических, коммуникативных, эмпатийных, рефлексивных и т.д.

\section{Выводы и научная новизна}

В результате можно прийти к следующим выводам: в современной культуре, для того чтобы добиться желаемого результата и успеха в профессиональной сфере, необходимо постоянно совершенствовать навыки речевого мастерства, повышать уровень своего интеллекта и культуры речи, коммуникативную механику, соблюдать правила речевого этикета в процессе формирования имиджа успешной личности.

Таким образом, результаты нашего исследования доказывают значимость речевого имиджа в процессе формирования индивидуального образа личности. При этом важно подчеркнуть, что, так как имидж возникает в результате целенаправленной активности со стороны субъекта, необходимо акцентировать внимание на трех наиболее обобщенных, интегральных переменных, характеризующих сущность целостной личности и ее индивидуальности: активность, направленность и саморегуляция.

В нашем исследовании выявлено, что речевые аспекты имиджа личности должны касаться как культуры речи (составляющей общей культуры человека), так и риторического или ораторского мастерства, а также языковой выразительности и техники речи.

Вместе с тем, важнейшую роль в процессе формирования речевого имиджа личности играет мастерство публичного выступления, владение которым не ограничивается только взаимодействием с аудиторией. В основе ораторского искусства лежат принципы риторики: подбор аргументов, их распределение в ходе логических доказательств, стиль и структура построения речи.

Формирование коммуникативных навыков - значимый аспект в построении речевого имиджа личности, необходимый ей не только в процессе профессионального взаимодействия, но и на протяжении всей ее жизнедеятельности.

Подводя итог рассмотренным выше положениям и результатам проведенного исследования, необходимо отметить, что глобальные социально-культурные преобразования, происходящие в современном обществе, выявили необходимость 
формирования образа успешной личности, владеющей грамотной, выразительной речью и способной эффективно выстраивать коммуникативный процесс. Полученные результаты требуют дальнейших исследований, доказывающих и демонстрирующих значение речевого имиджа в современном техногенном обществе.

1. Иссерс О.С. Коммуникативные стратегии и тактики русской речи: дис ... д-ра филол. наук. Омск, 1999. 385 с.

2. Калюжный А.А. Психология формирования имиджа учителя / Специальный курс «Риторика для учителя». М.: ВЛАДОС, 2004. 222 с.

3. Караулов Ю.Н. Русский язык и языковая личность. М.: Наука, 1987. 169 с.

4. Кормилицина М.Л., Сиротина О.Б. Хорошая речь / под ред. М.Л. Кормилицыной и О.Б. Сиротиной. 3-е изд. М.: ЛИБРОКОМ, 2009. 320 с.

5. Панасюк А.Ю. Формирование имиджа: стратегия, психотехнологии, психотехники. М.: Омега-Л, 2008. 266 с.

6. Перелыгина Е.Б. Психология имиджа. М.: Аспект Пресс, 2002. 223 с.

7. Фомина Н.А. Свойства личности и особенности речевой деятельности. Рязань: Узорочье, 2002. $213 \mathrm{c.}$

8. Формановская Н.И. Речевой этикет и культура общения. М.: Высшая школа, 2012. 160 с.

9. Шепель В.М. Как нравиться другим людям. М.: Народное образование, 2002576 с.

10. Яковлева Е.Л. Имидж и социальные роли // Политический маркетинг. 2004. № 7 (76). C. 9-14.

\section{Транслитерация}

1. Issers O.S. Kommunikativnye strategii i taktiki russkoi rechi : dis... d-ra filol. nauk. Omsk, 1999, $385 \mathrm{p}$.

2. Kalyuzhnyi A.A. Psikhologiya formirovaniya imidzha uchitelya / Spetsial'nyi kurs «Ritorika dlya uchitelya». M.: VLADOS, 2004, 222 p.

3. Karaulov Yu.N. Russkii yazyk i yazykovaya lichnost'. M.: Nauka, 1987, 169 p.

4. Kormilitsina M.L., Sirotina O.B. Khoroshaya rech'/ koll. monografiya pod red. M.L. Kormilitsynoi i O.B. Sirotinoi. 3-e izd. M.: LIBROKOM, 2009, 320 p.

5. Panasyuk A.Yu. Formirovanie imidzha: strategiya, psikhotekhnologii, psikhotekhniki. M.: «Omega-L», 2008, 266 p.

6. Perelygina E.B. Psikhologiya imidzha. M.: Aspekt Press, 2002, 223 p.

7. Fomina N.A. Svoistva lichnosti i osobennosti rechevoi deyatel'nosti. Ryazan': Uzoroch'e, 2002, 213 p.

8. Formanovskaya N.I. Rechevoi etiket i kul'tura obshcheniya. M.: Vysshaya shkola, 2012, 160 p.

9. Shepel' V.M. Kak nravit'sya drugim lyudyam. M.: Narodnoe obrazovanie, 2002, 576 p.

10. Yakovleva E.L. Imidzh i sotsial'nye roli, Politicheskii marketing, 2004, No 7 (76), pp. 9-14.

(C) Т.В. Метляева, 2018

Для цитирования: Метляева Т.В. Особенности формирования речевого имиджа личности // Территория новых возможностей. Вестник Владивостокского государственного университета экономики и сервиса. 2017. Т. 10. № 1. С. 156-164.

For citation: Metliaeva T.V. Peculiar characteristics of speech image formation, The Territory of New Opportunities. The Herald of Vladivostok State University of Economics and Service, 2018, Vol. 10, No 1, pp. $156-164$.

DOI dx.doi.org/10.24866/VVSU/2073-3984/2018-1/156-164

Дата поступления: 21.03.2018. 